\title{
Effects of Comorbid Fibromyalgia Syndrome on activities of daily living in multiple sclerosis patients
}

\author{
Efectos del Síndrome de Fibromialgia Comórbido en actividades cotidianas en \\ pacientes con esclerosis múltiple
}

Ersin Kasım ULUSOY

\begin{abstract}
Objective: To investigate the frequency of Comorbid Fibromyalgia Syndrome and its effects on quality of life and activities of daily living without any known psychiatric problem (schizophrenia or bipolar disorder) or severe disability, other than depression, in patients with multiple sclerosis, which is known to be a chronic disease in young adults. Methods: The study included 103 patients diagnosed with multiple sclerosis, following McDonald criteria, who had relapsing remitting disease. The Fibromyalgia Impact Questionnaire, Beck Anxiety Inventory, Beck Depression Inventory, Pittsburgh Sleep Quality Index, Fatigue Severity Scale, and Multiple Sclerosis Quality of Life-54 were applied for all patients. Results were analyzed using statistical methods. Results: Mean age was 35.04 8.72 years in the study population. The Expanded Disability Status Scale (EDSS) score was 2.21 \pm 0.93 . Comorbid Fibromyalgia Syndrome was detected in 20 patients (19.4\%). The mean score of Multiple Sclerosis Quality of Life-54 was found to be significantly higher in multiple sclerosis patients with Comorbid Fibromyalgia Syndrome when compared to those without it ( $34.80 \pm 9.14$ versus $71.67 \pm 13.95 ; p<0.05)$. Conclusion: These results indicate that increased frequency of Comorbid Fibromyalgia Syndrome in multiple sclerosis causes worsening in activities of daily living and quality of life, delayed diagnosis, disability progression, and increased admission rates. Questioning and appropriately managing Comorbid Fibromyalgia Syndrome in clinical practice are important to improve the quality of life in multiple sclerosis patients.
\end{abstract}

Keywords: Fibromyalgia; Quality of Life; Activities of Daily Living; Fatigue.

\section{RESUMEN}

Objetivo: Investigar la frecuencia del Síndrome de Fibromialgia Comórbido y sus efectos sobre la calidad de vida y las actividades cotidianas sin problemas psiquiátricos conocidos o discapacidad grave en pacientes con esclerosis múltiple, que se conoce como una enfermedad crónica en adultos jóvenes. Métodos: El estudio incluyó a 103 pacientes diagnosticados con esclerosis múltiple, según los criterios de McDonald, que tenían enfermedad remitente recurrente. En todos los pacientes se completaron: el Cuestionario de Impacto de Fibromialgia, el Inventario de Ansiedad de Beck, el Inventario de Depresión de Beck, el Índice de Calidad del Sueño de Pittsburgh, la Escala de Gravedad de Fatiga y la Calidad de Vida de la Esclerosis Múltiple-54. Los resultados se analizaron mediante métodos estadísticos.


(EDSS) fue de 2,21 $\pm 0,93$. Se detectó el Síndrome de Fibromialgia Comórbido en 20 pacientes (19,4\%). Se encontró que la puntuación media de la Calidad de Vida de la Esclerosis Múltiple-54 era significativamente más alta en pacientes de esclerosis múltiple con Síndrome

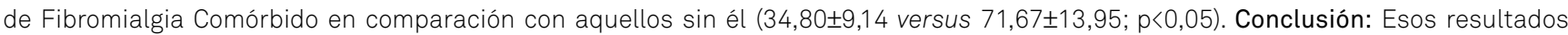
indican que el aumento de la frecuencia del Síndrome de Fibromialgia Comórbido en la esclerosis múltiple provoca empeoramiento de las actividades cotidianas y la calidad de vida, diagnóstico tardío, progresión de la discapacidad y mayores tasas de admisión. Cuestionar y manejar adecuadamente el Síndrome de Fibromialgia Comórbido en la práctica clínica son importantes para mejorar la calidad de vida en pacientes con esclerosis múltiple.

Palabras clave: Fibromialgia; Calidad de Vida; Actividades Cotidianas; Fatiga.

\section{INTRODUCTION}

Multiple sclerosis (MS) is an autoimmune, inflammatory, demyelinating, and neurodegenerative disorder that has been more commonly seen in women, which is characterized by relapsing neurological dysfunction. In developed countries, MS is the most common cause for neurological disability in younger adults. Relapsing remitting MS (RRMS) has been more commonly seen in younger age groups and has had a course characterized by attacks ${ }^{1,2,3}$.

'Kayseri Training and Research Hospital, Department of Neurology, Kayseri, Turkey.

Ersin Kasım ULUSOY (1D) https://orcid.org/0000-0001-7003-4597

Correspondence: Ersin Kasım Ulusoy; E-mail:ersinkasim_ulusoy@hotmail.com

Conflict of interest: There is no conflict of interest to declare.

Received on November 05, 2019; Received in its final form on April 08, 2020; Accepted on April 29, 2020. 
In addition to organic disorders, many physical and psychiatric comorbidities may develop during the disease course in MS patients. It has been reported that physical disorders, such as fibromyalgia syndrome (FMS), and psychiatric disorders, such as depression and anxiety disorders, euphoria, fatigue, sleep disorder, bipolar disorder and schizophrenia are frequently seen in MS patients who have been exposed to severe physical and psychosocial stressors. In previous studies, physical and psychiatric disorders were seen in approximately two-thirds of MS patients, even though treatment has not been indicated in all cases ${ }^{4,5}$.

FMS is a clinical condition that presents many symptoms, such as chronic, widespread pain and fatigue, sleep disorder, cognitive dysfunction, and depressive episodes ${ }^{6}$. It generally affects women aged 30-50. In previous studies, the prevalence of FMS was found as 1 to $4 \%$ in general population, while it varied between 0 and $4 \%$ among men and 2.5 to $10.5 \%$ among women. Quality of life is impaired due to physical and psychological disorders caused by FMS, which is associated with widespread pain (hyperalgesia and/or allodynia), tenderness in certain anatomic regions (tender points), chronic fatigue, sleep disorder, rigidity, and subjective swelling. Some literature studies suggest that comorbid FMS frequency is increased in MS patients, causing delayed diagnosis, disability progression, quality of life worsening, and hospitalization rate increase ${ }^{7}$.

This study aimed to investigate the frequency and effects of FMS on activities of daily living (ADL) without known psychiatric problem or severe disability in patients with MS, which is known to be a chronic disease in young adults.

\section{MATERIALS AND METHODS}

This study prospectively included patients with definitive MS diagnosis, based on McDonald criteria (2010), who were at the RR form interictal period and were followed up in 2017 and March, 2018 ${ }^{8}$. In all patients, diagnosis, identification of clinical form and follow-up were performed at the MS Outpatient Clinic of Kayseri Training and Research Hospital. The study was approved by the Local Ethics Committee and conducted following the Helsinki Declaration. All participants provided a written informed consent.

We recorded the age, gender, disease duration, medications, education level, occupation and neurological systems involved during disease course, findings of neurological examination, duration of follow-up, and overall number of attacks in all the patients. The Expanded Disability Status Scale (EDSS) was applied to assess functionality in MS patients9. Patients with EDSS score $>4.5$, younger than 18 or older than 50, with known FMS, menopausal women and that used neuropsychiatric agents six months before were excluded.
Diagnosis for FMS according to the American College of Rheumatology (ACR) 2016 revision should fulfil: generalized pain (at least four of five regions); persistent symptoms for at least three months; widespread pain index (WPI) $\geq 7$, and Symptom Severity Scale (SSS) score $\geq 5$ or WPI 4-6 and SSS score $\geq 9$; and a diagnosis of FMS is valid irrespective of other diagnoses, and a diagnosis of FMS does not exclude the presence of other clinically important illnesses ${ }^{10}$. The severity of FMS was assessed using the Fibromyalgia Impact Questionnaire (FIQ) with ten categories. Its score ranges from 0 to 80 points (maximum impact) ${ }^{11}$.

Quality of life was assessed by means of the MS Quality of Life Instrument (MSQOL-54), which analyzes and measures physical and mental health-related quality of life status (PHS and MHS, respectively). The item scores range from 0 (poor health) to 100 (optimal health). In addition, the multiple item scales of each of these scores can be analyzed individually to understand more clearly the changes on the composite scores. The physical health composite score is computed from the individual scores of the following scales: physical function, health perceptions, energy and fatigue, role limitations - physical, pain, sexual function, social function, and health distress. The mental health composite score is computed based on the individual scores of the following scales: health distress, overall quality of life, emotional well-being, role limitations - emotional, and cognitive function ${ }^{12,13}$.

Sleep disorder was assessed by means of Pittsburgh Sleep Quality Index (PSQI), which provides information about sleep quality and type and severity of sleep disorder in the prior month. Sleep quality is considered good when PSQI score is lower than five ${ }^{14}$. Anxiety was analyzed by means of Beck Anxiety Inventory (BAI). It provides four options in 21 symptom categories, and the highest scores indicated more severe anxiety ${ }^{15}$. Fatigue was assessed by means of the Fatigue Severity Scale (FSS), in which a mean value higher than four was considered an indication of clinically significant fatigue ${ }^{16}$. Depression was measured by means of the Beck Depression Inventory II (BDI-II). The cutoff scores used were: 0-13 for minimal depression; 14-19 for mild depression; 20-28 for moderate depression; and 29-63 for severe depression ${ }^{17}$.

All analyses were performed using the International Business Machines (IBMM) of the Statistical Package for the Social Sciences (SPSS) for Windows, version 20.0. Numerical variables are summarized as mean \pm standard deviation. Qualitative variables are presented as counting and percentages. For each continuous variable, normality was checked by the Kolmogorov-Smirnov test. Differences in numerical variables between the groups were also analyzed with the t-test for independent groups when the parametric test hypotheses were met, and with Mann-Whitney's U test, when they were not. Pearson's correlation coefficient was applied to assess the association between numerical variables. A p-value lower than 0.05 was statistically significant. 


\section{RESULTS}

Overall, 103 patients with RRMS were included in the study. Mean age was $35.04 \pm 8.72$ years (21-48) in the study population. Of the patients, 43 (52.4\%) were women, while 49 (47.6\%) were men. Mean age was $35.55 \pm 6.81$ years among women and $35.35 \pm 7.60$ years among men. Mean EDSS score was $2.20 \pm 0.88$ for females, whereas $2.21 \pm 0.97$ for males. Mean disease duration was $7.51 \pm 4.27$ years in the study population.

The FMS was detected in 20 patients (19.4\%) including 14 women (70\%) and 6 men (30\%). The most common comorbidity was fatigue (66\%); followed by depression (54.3\%), anxiety (50.4\%) and sleep disorder (48.5\%), as seen in Table 1.

Quality of life was assessed using the MSQOL-54 in MS


with FMS, while $72.67 \pm 13.95$ in those without FMS, indicating a significant difference between groups $(\mathrm{p}<0.001)$. When other comorbid conditions were assessed, depression, anxiety, fatigue, and sleep disorder were significantly more severe in MS patients with FMS ( $p<0.001)$. The EDSS score was significantly higher in MS patients with FMS than in those without it $(\mathrm{p}<0.05)$. No significant difference was detected in disease duration between MS patients with or without FMS ( $p>0.05$ ), as in Table 2.

Table 1. Comorbid conditions in multiple sclerosis patients.

\begin{tabular}{lcc}
\hline Comorbid conditions & Yes & No \\
\hline Fibromyalgia & $20(19.4 \%)$ & $83(80.6 \%)$ \\
Fatigue & $68(66 \%)$ & $35(44.0 \%)$ \\
Depression & $56(54.3 \%)$ & $47(45.7 \%)$ \\
\hline Anxiety & $52(50.4 \%)$ & $51(49.6 \%)$ \\
Sleep disorder & $50(48.5 \%)$ & $53(51.5 \%)$ \\
\hline
\end{tabular}

Table 2. Scales assessing activities of daily living and other comorbid conditions in multiple sclerosis patients with or without Comorbid Fibromyalgia Syndrome.

\begin{tabular}{|c|c|c|c|}
\hline $\begin{array}{l}\text { Comorbid } \\
\text { conditions }\end{array}$ & $\begin{array}{l}\text { With Comorbid } \\
\text { Fibromyalgia } \\
\text { Syndrome } \\
(n=20)\end{array}$ & $\begin{array}{c}\text { Without } \\
\text { Comorbid } \\
\text { Fibromyalgia } \\
\text { Syndrome }(n=83)\end{array}$ & $\mathrm{p}$-value \\
\hline $\begin{array}{l}\text { Activities of } \\
\text { daily living }\end{array}$ & $34.80 \pm 9.14$ & $71.67 \pm 13.95$ & $<0.001^{a}$ \\
\hline Anxiety & $29.25 \pm 8.05$ & $10.19 \pm 6.33$ & $<0.001^{a}$ \\
\hline Depression & $26.95 \pm 7.85$ & $11.66 \pm 6.23$ & $<0.001^{a}$ \\
\hline $\begin{array}{l}\text { Sleep } \\
\text { disorder }\end{array}$ & $10.00 \pm 2.15$ & $4.69 \pm 2.11$ & $<0.001^{a}$ \\
\hline Age & $37.55 \pm 5.34$ & $34.95 \pm 7.47$ & 0.146 \\
\hline $\begin{array}{l}\text { Disease } \\
\text { duration/year }\end{array}$ & $9.85 \pm 3.54$ & $6.95 \pm 4.25$ & $0.006^{a}$ \\
\hline EDSS & $3.50 *$ & $2.00 *$ & $<0.001^{b}$ \\
\hline Fatigue & $6.71 *$ & $4.24^{\star}$ & $<0.001^{b}$ \\
\hline
\end{tabular}

aindependent Student's $t$-test; 'Mann-Whitney's $U$ test; significant p-values $(p<0.05)$ are given in italic type; ${ }^{*}$ median values are given; EDSS: Expanded Disability Status Scale.
There was a significant and negative correlation between FIQ and MSQOL-54 in patients with FMS $(p<0.05)$, as in Figure 1. In addition, there were significant positive correlations between FIQ and BAI or BDI $(p<0.05)$. However, the positive correlations with PSQI, FSS and EDSS scores did not reach statistical significance ( $p>0.05)$, based on Table 3 .

In the MSQOL-54 test, mean score of physical health domain was 33.61 10.06 in MS patients with FMS, whereas $71.60 \pm 12.86$ in those without it. The mean score of cognitive health domain was 35.99 \pm 9.42 in MS patients with FMS, whereas $71.73 \pm 16.00$ in those without it. Differences in both domains were found to be statistically significant $(\mathrm{p}<0.05)$.

\section{DISCUSSION}

In our study, we investigated the effects of FMS frequency on ADL as well as anxiety, depression, fatigue, and sleep disorder in MS patients. Our results revealed that ADL were significantly more impaired in MS patients with FMS that in those without it. In the subgroup analysis, there was

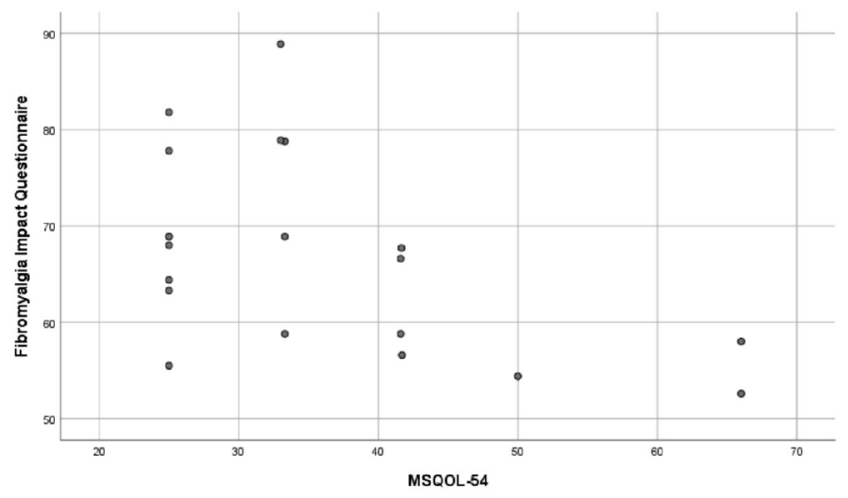

MSQOL-54: Multiple Sclerosis Quality of Life Instrument.

Figure 1. Correlations between fibromyalgia impact questionnaire and activities of daily living.

Table 3. Correlations between the Fibromyalgia Impact Questionnaire and other comorbid conditions.

\begin{tabular}{|c|c|c|}
\hline \multicolumn{3}{|c|}{ Fibromyalgia Impact Questionnaire } \\
\hline & $r$ & $p$-value* \\
\hline Beck Anxiety & 0.533 & 0.016 \\
\hline Beck Depression & 0.726 & $<0.001$ \\
\hline PSQl & 0.292 & 0.212 \\
\hline FSS & 0.202 & 0.392 \\
\hline EDSS & 0.373 & 0.105 \\
\hline Disease duration/year & -0.067 & 0.780 \\
\hline
\end{tabular}

${ }^{*} \mathrm{p}$ : Pearson's correlation coefficient; PSQI: Pittsburgh Sleep Quality Index; FSS: Fatigue Severity Scale; EDSS: Expanded Disability Status Scale. 
a significant difference in the frequency of anxiety, depression, fatigue, and sleep disorders between MS patients with or without FMS.

Although the etiopathogenesis of FMS could not be fully established, hormonal disorders, dysfunction of nervous system, immune problems, micro-circulation disorders in muscles and genetic predisposition may be involved in FMS. In some studies, FMS prevalence was reported to be 2 to $7 \%$ in general population with female preponderance ${ }^{18}$. In a study on MS patients and healthy volunteers, Marrie et al. found that FMS frequency was 3.5 folds higher in MS patients when compared to the general population ${ }^{19}$. However, to the best of our knowledge, there is no study addressing FMS frequency in the context of ADL and its effects on sleep and chronic fatigue. In our study, FMS frequency was increased by 3.5 folds in MS patients in agreement with literature. In addition, this increase was associated with impairment in ADL, sleep disorder, and chronic fatigue. Our findings show that early diagnosis and timely intervention to FMS in MS patients will result in improvement in ADL and quality of life. Moreover, effectiveness and tolerability to primary drugs might be improved with FMS treatment.

The presence of comorbid FMS in MS patients has been associated with increased disability, decreased labor force, ADL and quality of life, and social losses. However, the relationship between FMS and MS has not been fully elucidated ${ }^{19}$. In MS patients, the FMS has been seen upon early phases of disease, and incidence increases as disability severity becomes higher. However, the varying prevalence rates for FMS were found in different series. Therefore, the presence of FMS varies according to age, gender, geographic region, disability status, and comorbid conditions. Clemenzi et al. found a FMS frequency of $17.3 \%$ in MS patients and $3.8 \%$ in the general population $^{20}$. In a cohort study by Davis et al., FMS frequency was reported as $14.06 \%$ in MS patients ${ }^{21}$. Authors reported that FMS frequency was higher among women and that it was increased when EDSS scores were higher. In our study, MS patients with EDSS $>4.5$ were excluded to standardize our work and to show that it may be FMS in the early phase of the disease. Furthermore, FMS frequency was $19.4 \%$ and FMS could be seen upon the early phases of MS and it increased by making EDSS score higher, which is in agreement with previous literature. In addition, FMS presence was independent from age and disease duration, and marked female preponderance was present.

Besides FMS, the incidence of several physical and psychiatric comorbidities, such as depression, anxiety, fatigue or sleep disorder, is markedly higher in MS patients, affecting more than $50 \%$ of patients ${ }^{22}$. Depression is the most common psychiatric disorder seen in MS, which is a chronic disease resulting in disability in young adults. Depression prevalence ranged from 27 to $54 \%$ in several series using different, but valid, scales ${ }^{23,24}$. It is seen three folds higher than other chronic diseases. Lifetime prevalence of depression is higher than other medical and neurological diseases in MS patients. It is accepted that depression seen in MS may be due to the combination of organic and psychological effects of MS. Anxiety is another widely seen psychiatric comorbidity in $\mathrm{MS}^{25}$. In a study by Stenager et al., a significant relationship was reported between anxiety and physical losses. FMS and depression share similar pathophysiological pathways. However, the relationship between depression and increase in FMS has not been assessed in studies on MS patients. In our study, we concluded that the presence of MS is correlated with FMS development in MS. In subgroup analysis, we found that depression and anxiety severity was increased in MS patients with FMS.

MS-related fatigue is defined as physical and mental energy deprivation observed by patient or caregiver. In previous studies, 75 to $87 \%$ of MS patients suffered from fatigue. Of these patients, two-thirds reported it as one of the three worst symptoms of the disease ${ }^{25}$. In MS, fatigue is more frequent when compared to healthy adults and individuals with chronic disorders and has more influence on ADL. The fatigue incidence has been reported as 78 to $94 \%$. However, no specific underlying mechanism has been revealed for fatigue seen in FMS or $\mathrm{MS}^{26}$. In a study on 207 MS patients, Kroencke et al. assessed patients using the FSS and SelfRating Depression scales. Authors found that fatigue scores were highly correlated with depression scores and EDSS ${ }^{27}$. However, the effect of FMS on fatigue has not been evaluated so far. In our study, we found that fatigue severity was higher in MS patients with FMS.

Sleep disorder is another comorbid condition in MS patients, considering that perceived stress is higher in MS patients when compared to healthy individuals ${ }^{28}$. In a study on MS patients, Figved et al. investigated neuropsychiatric symptoms and found that sleep disorder is the second most common comorbidity (48\%) following depression in MS patients $^{29}$. In our study, sleep quality was assessed through the PSQI and impaired sleep quality was found in MS patients with FMS when compared to those without it.

Although comorbid FMS and psychiatric disorders have been assessed in large series and population-based studies, their effects on ADL, fatigue and sleep disorder and their correlation among each other have not been evaluated. Relatively small sample size and lack of comparison with health controls are limitations of our study. Another limitation is that the study included only the RRMS. It is known that such comorbidities are more common, and $\mathrm{ADL}$ are more strongly affected in progressive forms of MS. This may lead to an underestimation of our results.

In conclusion, FMS and accompanying anxiety, depression, fatigue, and sleep disorders are a commonly seen comorbidity in MS patients. They can be seen in every phase of MS without the presence of severe disability. Comorbid conditions can be overlooked since clinicians focus on the 
treatment of primary disease. These comorbidities lead to a delay in diagnosis, disability progression, decreased quality of life, and increased admission rates. To the best of our knowledge, there is no study addressing effects of FMS on quality of life in MS patients. Our study is the first showing such relationship. Questioning and appropriately managing FMS in clinical practice are important to improve quality of life in MS patients.

\section{References}

1. Confavreux C, Vukusic S, Moreau T, Adeleine P. Relapses and progression of disability in multiple sclerosis. N Engl J Med. 2000 Nov;343(20):1430-38. https://doi.org/10.1056/nejm200011163432001

2. Benito-León J, Morales JM, Rivera-Navarro J. Health-related quality of life and its relationship to cognitive and emotional functioning in multiple sclerosis patients. Eur J Neurol. 2002 Sep;9(5):497-502. https://doi.org/10.1046/j.1468-1331.2002.00450.x

3. Marrie RA, Yu N, Blanchard JF, Leung S, Elliott L. The rising prevalence and changing age distribution of multiple sclerosis in Manitoba. Neurology. 2010 Feb;74(6):465-71. https://doi. org/10.1212/WNL.0b013e3181cf6ec0

4. Fromont A, Binquet C, Rollot F, Despalins R, Weill A, Clerc L, et al. Comorbidities at multiple sclerosis diagnosis. J Neurol. 2013 Oct;260(10):2629-37. https://doi.org/10.1007/s00415-013-7041-9

5. Alschuler KN, Jensen MP, Ehde DM. The association of depression with pain-related treatment utilization in patients with multiple sclerosis. Pain Med. 2012 Dec;13(12):1648-57. https://doi. org/10.1111/j.1526-4637.2012.01513.x

6. Desmeules JA, Cedraschi C, Rapiti E, Baumgartner E, Finckh $A$, Cohen P, et al. Neurophysiologic evidence for a central sensitization in patients with fibromyalgia. Arthritis Rheum. 2003 May;48(5):1420-9. https://doi.org/10.1002/art.10893

7. Thormann A, Sørensen PS, Koch-Henriksen N, Laursen B, Magyari M. Comorbidity in multiple sclerosis is associated with diagnostic delays and increased mortality. Neurology. 2017 Oct;89(16):1668-75. https://doi.org/10.1212/wnl.0000000000004508

8. Polman CH, Reingold SC, Banwell B, Clanet M, Cohen JA, Filippi M, et al. Diagnostic criteria for multiple sclerosis: 2010 revisions to the McDonald criteria. Ann Neurol. 2011 Feb;69(2):292-302. https://doi. org/10.1002/ana.22366

9. Kurtzke JF. Rating neurologic impairment in multiple sclerosis: an expanded disability status scale (EDSS). Neurology. 1983 Nov;33(11):1444-52. https://doi.org/10.1212/wnl.33.11.1444

10. Wolfe F, Clauw DJ, Fitzcharles MA, Goldenberg DL, Häuser W, Katz RL, et al. 2016 Revisions to the 2010/2011 fibromyalgia diagnostic criteria. Semin Arthritis Rheum. 2016 Dec;46(3):319-29. https://doi. org/10.1016/j.semarthrit.2016.08.012

11. Bennett R. The Fibromyalgia Impact Questionnaire (FIQ): a review of its development, current version, operating characteristics and uses. Clin Exp Rheumatol. Sep-Oct 2005;23(5 Suppl 39):S154-62.

12. Tabrizi FM, Radfar M. Fatigue, sleep quality, and disability in relation to quality of life in multiple sclerosis. Int J MS Care. 2015 NovDec;17(6):268-74. https://doi.org/10.7224/1537-2073.2014-046 .

13. Heiskanen S, Meriläinen P, Pietilä AM. Health-related quality of life-testing the reliability of the MSQOL-54 instrument among MS patients. Scand J Caring Sci. 2007 Jun;21(2):199-206. https://doi. org/10.1111/j.1471-6712.2007.00456.x

14. Buysse DJ, Reynolds 3rd CF, Monk TH, Berman SR, Kupfer DJ. The Pittsburgh Sleep Quality Index: a new instrument for psychiatric practice and research. Psychiatry Res. 1989 May;28(2):193-213. https://doi.org/10.1016/0165-1781(89)90047-4

15. Beck AT, Epstein N, Brown G, Steer RA. An inventory for measuring clinical anxiety: psychometric properties. J Consult Clin Psychol. 1988 Dec;56(6):893-7. https://doi.org/10.1037//0022-006x.56.6.893
16. Kaynak H, Altintaș A, Kaynak D, Uyanik O, Saip S, Ağaoğlu J, et al. Fatigue and sleep disturbance in multiple sclerosis. Eur J Neurol. 2006 Dec;13(12):1333-9. https://doi.org/10.1111/j.14681331.2006.01499.x

17. Smarr KL, Keefer AL. Measures of depression and depressive symptoms: Beck Depression Inventory-II (BDI-II), Center for Epidemiologic Studies Depression Scale (CES-D), Geriatric Depression Scale (GDS), Hospital Anxiety and Depression Scale (HADS), and Patient Health Questionnaire-9 (PHQ-9). Arthritis Care Res (Hoboken). 2011 Nov;63 Suppl 11:S454-66. https://doi. org/10.1002/acr.20556

18. Kwiatek R. Treatment of fibromyalgia. Aust Prescr. 2017 Oct;40(5):179-83. https://doi.org/10.18773/austprescr.2017.056

19. Marrie RA, Patten SB, Tremlett H, Wolfson C, Warren S, Svenson LW, et al. Sex differences in comorbidity at diagnosis of multiple sclerosis: a population-based study. Neurology. 2016 Apr5;86(14):1279-86. https://doi.org/10.1212/ WNL.0000000000002481

20. Clemenzi A, Pompa A, Casillo P, Pace L, Troisi E, Catani S, et al. Chronic pain in multiple sclerosis: Is there also fibromyalgia? An observational study. Med Sci Monit. 2014 May;20:758-66. https://doi. org/10.12659/MSM.89000

21. Davis JA, Robinson RL, Le TK, Xie J. Incidence and impact of pain conditions and comorbid illnesses. J Pain Res. 2011;4:331-45. https://doi.org/10.2147/JPR.S24170

22. Fiest KM, Fisk JD, Patten SB, Tremlett H, Wolfson C, Warren S, et al. Comorbidity is associated with pain-related activity limitations in multiple sclerosis. Mult Scler Relat Disord. 2015 Sep;4(5):470-76. https://doi.org/10.1016/j.msard.2015.07.014

23. Marrie RA, Horwitz RI, Cutter G, Tyry T, Campagnolo D, Vollmer T. Comorbidity delays diagnosis and increases disability at diagnosis in MS. Neurology. 2009 Jan;72(2):117-24. https://doi.org/10.1212/01. wnl.0000333252.78173.5f

24. Sadovnick AD, Remick RA, Allen J, Swartz E, Yee IM, Eisen $\mathrm{K}$, et al. Depression and multiple sclerosis. Neurology. 1996 Mar;46(3):628-32. https://doi.org/10.1212/wnl.46.3.628

25. Stenager E, Knudsen L, Jensen K. Multiple sclerosis: correlation of anxiety, physical impairment and cognitive dysfunction. Ital J Neurol Sci. 1994;15(2):97-101. https://doi.org/10.1007/BF02340120

26. Edwards NC, Munsell M, Menzin J, Phillips AL. Comorbidity in US patients with multiple sclerosis. Patient Relat Outcome Meas. 2018;9:97-102. https://doi.org/10.2147/PROM.S148387

27. Kroencke DC, Lynch SG, Denney DR. Fatigue in multiple sclerosis: relationship to depression, disability, and disease pattern. Mult Scler. 2000 Apr;6(2):131-6. https://doi.org/10.1177/135245850000600213

28. Merlino G, Fratticci L, Lenchig C, Valente M, Cargnelutti D, Picello M, et al. Prevalence of'poor sleep'among patients with multiple sclerosis: an independent predictor of mental and physical status. Sleep Med. 2009 Jan;10(1):26-34. https://doi.org/10.1016/j. sleep.2007.11.004

29. Figved N, Klevan G, Myhr KM, Glad S, Nyland H, Larsen JP, et al. Neuropsychiatric symptoms in patients with multiple sclerosis. Acta Psychiatr Scand. 2005 Dec;112(6):463-8. https://doi.org/10.1111/ j.1600-0447.2005.00624.x 